\title{
A Delphi-AHP study on STCW leadership competence in the age of autonomous maritime operations
}

\author{
Tae-eun $\mathrm{Kim}^{1} \cdot$ Steven Mallam ${ }^{1}$ (D) \\ Received: 24 January 2020 / Accepted: 8 May 2020 / Published online: 26 May 2020 \\ (C) The Author(s) 2020
}

\begin{abstract}
Accelerating technological advancement in the maritime industry is gradually increasing the range of functions once performed by humans to become automated. In the era of autonomous shipping, where the autonomous operating system takes the lead and data flows define decision-making, how the ship and its leaders can successfully navigate these new ways of working have important implications for safety, efficiency and reliability of future ship operations. It is critical that the non-technical skills requirements, in particular the leadership competencies, be re-evaluated as new operational paradigms of shipping systems emerge and evolve. This study extends the current research of Maritime Autonomous Surface Ships (MASS) by using a Delphi consensus survey and Analytic Hierarchy Process (AHP) with a panel of 36 experts to (1) bridge a knowledge gap, i.e., the lack of an understanding regarding the leadership implication of autonomous shipping; (2) evaluate the applicability of current STCW leadership requirements for MASS operations; (3) identify and prioritize the leadership competences that should be accrued by the personnel involved in future ship operations. The results have shown that the current STCW framework is not fully relevant for MASS. The redefined leadership competence and the constructed hierarchy of criticality generated from this study can be valuable input for revision of the STCW and maritime education and training practices, contributing to successful ship operations of the future.
\end{abstract}

Keywords MASS $\cdot$ MET $\cdot$ Leadership $\cdot$ Human element $\cdot$ IMO

Steven Mallam

Steven.Mallam@usn.no

1 Department of Maritime Operations, Faculty of Technology, Natural Sciences and Maritime

Sciences, University of South-Eastern Norway (USN), Vestfold, Norway 


\section{Introduction}

The maritime industry is undergoing a wave of increased automation and digitalization, while interest and development of unmanned, remotely controlled and autonomous vessels are flourishing (Porathe et al. 2018; Ringbom 2019; WMU and ITF 2019).

Remotely controlled and autonomous shipping solutions have the potential of addressing many concerns the industry currently faces - such as seafarer shortages, welfare of seagoing personnel, safety and reliability of ship operations, improved fuel consumption and operational efficiency - through reducing or reorganizing the workload of human operators, manning requirements and the risks associated with human failures (i.e., errors or violations) (Komianos 2018; Porathe et al. 2018; Pribyl and Vessels 2018). Pioneered by several exploratory Maritime Autonomous Surface Ships (MASS) projects (e.g., "Iris Leader," "Yara Birkeland," "MUNIN"), the area of autonomous and remote operation for surface ships is evolving around the globe (Pribyl and Weigel 2018; WMU and ITF 2019). Besides the numerous anticipated advantages, research has revealed scepticism toward proposed benefits. Challenges, including safety and cyber security issues (Montewka et al. 2018; Kavallieratos et al. 2019), economic feasibility (Santos and Guedes Soares 2018), operational challenges (Kooij et al. 2018) and regulatory acceptance (Ringbom 2019) as well as other nontechnical hurdles are yet to be solved (Bertram 2016; Mallam et al. 2019b).

As global shipping sails into a more autonomous future, the potential impact of MASS on the competence requirement of global seafarers should not be overlooked. Moving towards highly automated, remotely controlled or autonomous solutions implies that the routines of ship operations and the roles, duties and responsibilities as well as the leadership displayed by the shipboard leaders (e.g., masters, chief officers, chief engineers and second engineers) will be radically different compared with conventional shipboard organization (Kitada et al. 2018). The existence of these positions may also be in jeopardy (Sharma et al. 2019). How the ship and its leaders navigate these new ways of working has important implications for the safety and reliability of ship operations. The leadership knowledge, understanding and proficiencies (KUP) as required in the International Convention on Standards of Training, Certification and Watchkeeping 1978, as amended (STCW 1978), that have yielded safe and effective operations in the past may no longer be as relevant or effective when automation is implemented to higher degrees (Sharma et al. 2019). Therefore, it is critical that the STCW leadership strategies be re-evaluated in this new context to adequately take advantage of autonomous shipping potentials.

As of present, there has been little discussion on the potential impact of autonomous shipping on leadership and organization of shipboard personnel (Kitada et al. 2018). No research to date has evaluated the applicability and relevance of current STCW leadership requirements under different MASS operational situations. Bolden and O'Regan (2016) state that digital technology has "significant implications for leadership theory, practice, and development that, as yet, remain largely unexplored in mainstream academic literature" (p. 438). By following up on the research trend on MASS, this paper aims to address this gap by investigating the leadership implication of autonomous shipping, evaluating the STCW leadership requirements to cope with increased autonomy and exploring the future leadership competences that should be accrued by the personnel involved in the ship operations. 


\section{Research scope and background}

\subsection{Manned, unmanned and remotely controlled MASS}

The International Maritime Organization (IMO) defines a MASS as "a ship which, to a varying degree, can operate independent of human interaction" (IMO 2018). For the purpose of the regulatory scoping exercise on MASS, four degrees of autonomy have been established by IMO (IMO 2018), as illustrated in Fig. 1.

According to this scale (IMO 2018), degree 1 level of autonomy involves seafarers onboard to operate and control the shipboard systems and functions. Under degrees 2 and 3, the ship is controlled and operated by remote control operators from another location. Seafarers are available onboard to take control in degree 2, whereas the ship is unmanned and remotely controlled in degree 3 . In degree 4 , the ship is fully autonomous as the operating system will be able to make decisions and determine actions by itself and operate independently of direct human interaction (IMO 2018). With the involvement of operators remotely operating the MASS, it can be expected that those operators will also need to be trained and certificated in accordance with mandatory minimum requirements set out in future versions of STCW (Ringbom 2019; Sharma et al. 2019). It is noted that the degree of autonomy is not necessarily intended to be linear or hierarchical; MASS can operate at one or more degrees of autonomy during a single voyage.

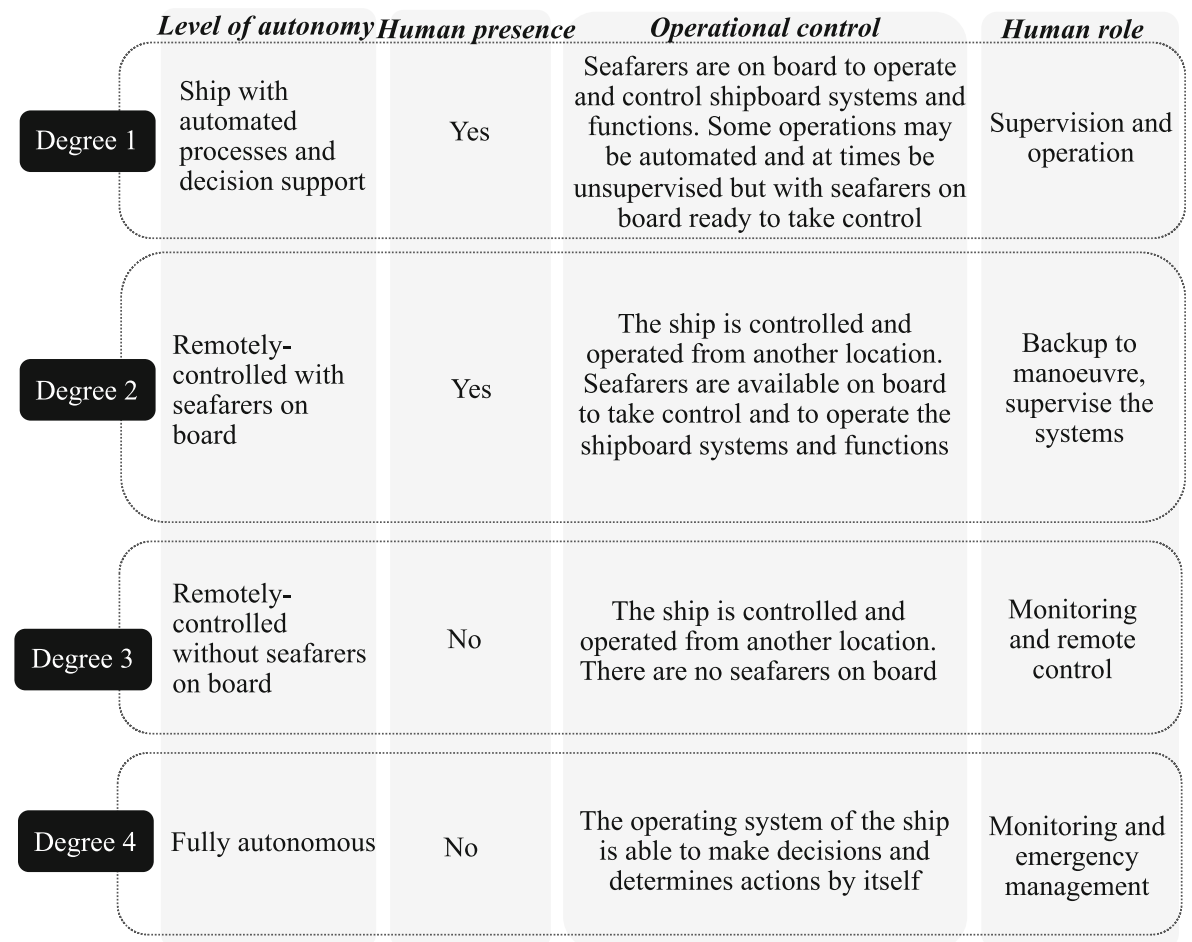

Fig. 1 MASS's level of automation (adapted from IMO 2018, Kim et al. 2019) 
To limit the scope of our research and frame our discussions, this research considered two MASS areas as the main focus of this study: manned MASS and unmanned and remotely controlled MASS, corresponding to degree 1 and degree 3 automation in according to IMO's definition (IMO 2018).

\subsection{Shipboard organization and leadership requirement}

Ship operations conventionally depend on a high degree of human involvement. Many of the functions and tasks onboard ships, such as navigation, propulsion, cargo security, mooring and anchoring, have traditionally required the attendance of one or several people for carrying out the tasks for successful and safe operations. The masters and crews who operate ships today are the on-scene operators, problem solvers, decision makers, repairmen and physical security providers, who make shipping a safe, secure, efficient and economical transport solution.

Throughout history, the advent of new technologies, increased reliability and efficacy of automated systems have gradually reduced the manning level onboard ships required to carry out functions. A historical example of this is the migration from the coal-fired steam engine propulsion to diesel-powered engines during the twentieth century. This new technology and propulsion solution enabled the size of the engineroom crews to reduce due to the change in work tasks and requirements for operation. Advances in propulsion technology and automation have allowed a typical engineering crew of several hundred (e.g., 211 onboard the Titanic in 1912) (Titanicfacts 2020) to in many cases less than 10 in attendance today for carrying out ship functions and maintenance. In general, most merchant vessels today typically require a crew team of 15 to 26 personnel (Cambanis 2011), which consists of officers (e.g., master, chief mate, second mate, chief engineer, second engineer), specialist technicians (e.g., electricians, mechanics) and ratings (e.g., bosun, able seaman, ordinary seaman, wiper, cooks and oilers).

The conventional organizational structure of a merchant ship emphasizes a strong hierarchy and a clear path of accountability to govern performance. When a ship is at sea, the master has the highest responsibility for the safe and efficient execution of the voyage and all operations, whose authority at sea is supreme and overriding (Cartner et al. 2009). Masters carry the ultimate responsibility for the safety of all cargo and crew onboard. Furthermore, there are many other obligations and rights vested in the master under current national legislation and international conventions (e.g., Danish Maritime Authority 2017; IMO 2017). The master and other shipboard managers' decision making, judgment and leadership styles have vital influence towards the crews and the way the ship is managed and operated in daily and abnormal situations.

The STCW 1978 as amended have included leadership training as a mandatory competence requirement for officers at both management and operational level (e.g., masters, chief officers, chief engineers and second engineers) (STCW 1978). The specific leadership knowledge, understanding and proficiency (KUP) as set out in Table A-II/2 (for masters and chief mates), Table A-III/2 (for chief engineer officers and second engineer officers), Table A-II/1 (for officers in charge of a navigational watch) and Table A-III/1 (officers in charge of an engineering watch) (STCW 1978) are summarized in Table 1. 
Table 1 Required leadership competence for management and operational level onboard conventional merchant ships set out in STCW code Table A-II/2, Table A-III/2, Table A-II/1 and Table A-III/1 (STCW 1978)

\begin{tabular}{|c|c|}
\hline Target & Knowledge, understanding and proficiency (KUP) \\
\hline \multirow{6}{*}{$\begin{array}{l}\text { STCW required leadership competence for both } \\
\text { management and operational level onboard } \\
\text { conventional merchant ships }\end{array}$} & $\begin{array}{l}\text { KUP 1: Knowledge of shipboard personnel } \\
\text { management and training }\end{array}$ \\
\hline & $\begin{array}{l}\text { KUP 2: Knowledge of related international maritime } \\
\text { conventions and recommendations and national } \\
\text { legislation }\end{array}$ \\
\hline & $\begin{array}{l}\text { KUP 3: Ability to apply task and workload } \\
\text { management, including: } \\
.1 \text { planning and coordination } \\
.2 \text { personnel assignment } \\
.3 \text { time and resource constraints } \\
.4 \text { prioritization }\end{array}$ \\
\hline & $\begin{array}{l}\text { KUP } 4 \text { : Knowledge and ability to apply effective } \\
\text { resource management: } \\
.1 \text { allocation, assignment, and prioritization of } \\
\text { resources } \\
.2 \text { effective communication on board and ashore } \\
.3 \text { decisions reflect consideration of team experience } \\
.4 \text { assertiveness and leadership, including motivation } \\
.5 \text { obtaining and maintaining situation awareness }\end{array}$ \\
\hline & $\begin{array}{l}\text { KUP 5: Knowledge and ability to apply } \\
\text { decision-making techniques: } \\
.1 \text { situation and risk assessment } \\
.2 \text { identify and generate options } \\
.3 \text { select course of action } \\
.4 \text { evaluation of outcome effectiveness }\end{array}$ \\
\hline & $\begin{array}{l}\text { KUP 6: Development, implementation and oversight } \\
\text { of standard operating procedures (*only for } \\
\text { management level) }\end{array}$ \\
\hline
\end{tabular}

In addition to these leadership requirements as outlined in STCW 1978 as amended (STCW 1978), research has also examined other elements of leadership competence, such as actual shipboard leaders' practices and behaviours and their impact for safety and efficiency. Studies have revealed that many of the contributing factors to maritime accidents (e.g., poor safety culture, dysfunctional teamwork, poor communication, ineffective implementation of the safety management system) can be traced to the failure of leadership for safety (Kim et al. 2016). The likelihood of subordinates' safety compliance and safety participation are determined by the safety culture and the leaders' behaviours they are modelling (Griffin and Neal 2000; Kim et al. 2016; Mallam et al. 2019a; Kim and Gausdal 2020), their safety commitment and engagement are highly influenced by perceived organizational support and the quality of interpersonal relationships (Eid et al. 2012). By synthesizing the literature, Kim and Gausdal (2017) derived four leadership behavioural categories that are essential for safety at the shipboard level, which are communicating (i.e., facilitate effective communication on board and ashore, foster open and frequent feedback pertaining safety issues); caring and supporting (i.e., respect and trust the crew members, care about their needs and 
empathize with their problems); controlling and enforcing (i.e., set the rules by which the organization runs, use their power to give a reward or a punishment); Participative involvement (i.e., promote crew members' involvement in decision making and their participation in safety activities) (Kim and Gausdal 2017).

Among these, participative involvement from the shipboard management has been perceived as having the highest importance and contribution to safety performance in ship operations (Kim and Gausdal 2017). Participative involvement opens the way for collecting feedback and input from the crew members to improve work procedures and systems design to prevent future recurrences of error (Kim and Gausdal 2017). As communication category overlaps with KUP 4.2 (see Table 1), there are total 6 KUPs and 3 additional leadership behavioural categories that should be evaluated.

Introducing novel technologies for autonomous and remote control of ship functions is, in theory, making it possible to reduce or even eliminate onboard crews in both deck and engine departments and re-organize the work tasks, demands and structure for those reduced crews. If unmanned and autonomous shipping continues to develop and proliferate, the function allocation and shipboard management, as we know today, could be radically different in the future. As shown in Fig. 2, contrasting the manned MASS leadership model (left), the ship automated operating system can act as a middle manager and conduct the ship operation in accordance to the goals and standards defined by the human leaders at the upper level (e.g., ship owners, fleet manager) (right).

Moreover, within this scenario, it can be presumed that many of the obligations and leadership functions resting with the masters today in conventional ships will be distributed between the autonomous operating system and shore-based human operators. This, in turn, is linked to the question of whether traditional leadership knowledge, styles and practices that are defined in human relationships will still be applicable and important under autonomous ship operations. Furthermore, in the case that a ship is remotely controlled, can the leadership role be taken over by remote control operators? If yes, then what kind of leadership practices are needed for remote control operators in autonomous ship operations? These questions guide the direction and objective of this research.

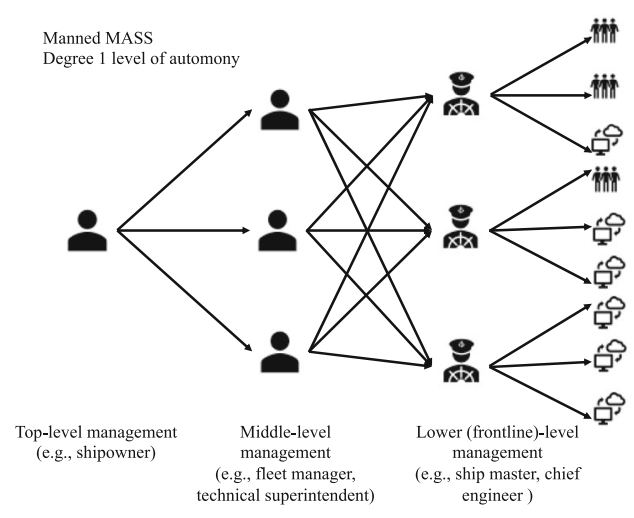

Fig. 2 Hierarchical leadership relation in comparison
Remote-controlled and unmanned MASS Degree 3 level of automony

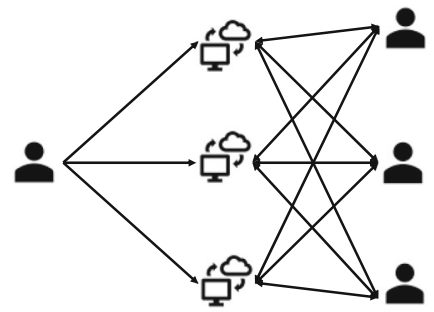

Top-level management Autonomous operating Shore-control center $\begin{array}{lrr}\text { (e.g., shipowner) } & \text { systems } & \text { operators }\end{array}$ 


\section{Methodology and research process}

To address the research questions, this study was endowed with two methodological phases integrating the Delphi technique (Murry Jr and Hammons 1995) and Analytic Hierarchy Process (AHP) (Saaty 2003) with two sequential surveys seeking to collect empirical data from the experts. The surveys do not collect any personal identifiable information. Delphi is a structured consensus building method used to derive experts' opinion and to determine the extent of agreement on a specific topic through structuring a communication process, which typically involves two or three "rounds" in which selected experts respond to questions until reaching a good level of consensus (Hsu and Sandford 2007). In this study, by building on the results derived from Delphi, a mathematically grounded technique for multiple-criteria decision makingAHP (Saaty 2003) - was applied to rank the leadership competence requirements based on their relative importance under different MASS operational situations and to identify the critical leadership competence that plays the principal role. AHP incorporates expert's judgments, uses pair-wise comparison method and generates ratio data, which could tell the relative importance of an item in comparison with another and determine an overall ranking of the alternatives (Podvezko 2009; Chelst and Canbolat 2011). As a mature and well-accepted decision-making method, AHP has been widely applied to a diverse array of research problems in various domain (Saaty 2002; Vaidya and Kumar 2006). The overall research process is presented in Fig. 3.

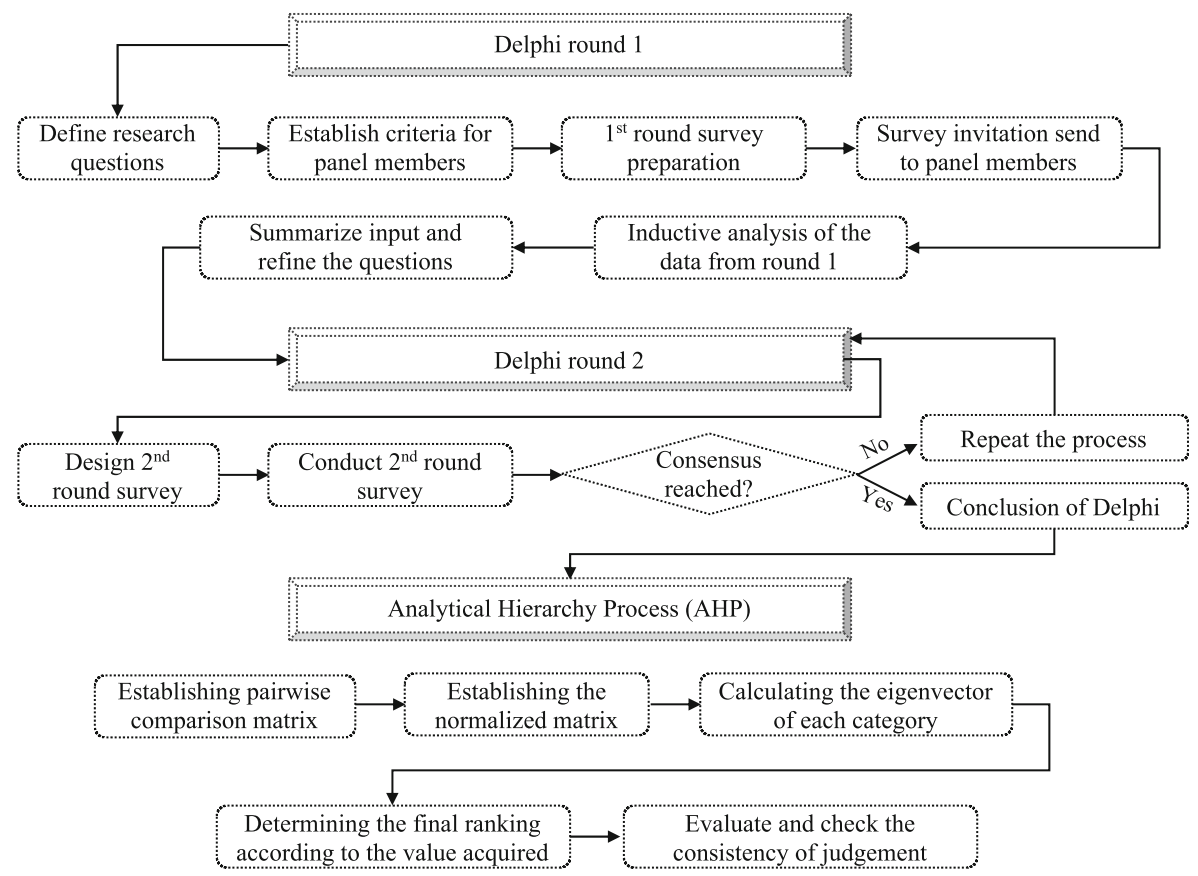

Fig. 3 Flowchart of research process 


\subsection{Panel selection}

The panellists to be selected were required to have relevant experience and expertise in the field of maritime leadership training, maritime research or professional seafarers (see Table 2). We picked the first six experts and asked them to refer to other experts they know who could fit the description of samples needed, which correspond to a snowball sampling process (Biernacki and Waldorf 1981). In total, thirty-six panellists participated in this study, in which 24 panellists completed the first round of Delphi survey. A heterogeneous panel with 12 experts was established for the second round to verify the first round output and to add new perspective and insight.

As shown in Table 2, there are over $36 \%$ of the panellists who have more than 15 years' experience in the maritime industry while holding positions such as ship owners, non-technical skills training providers, masters, chief officers, chief engineers or port operators. Further, majority of the panellists have experience as a professional seafarer or maritime researcher in the field of leadership training and/or MASS research, constituting a reasonable expert panel for the study to generate appropriate and representative findings.

\subsection{Delphi and AHP procedure}

In the first round of the Delphi survey, a questionnaire consisting of two sections was used to elicit opinions from the panellists on the contemporary development of autonomous maritime operations and the perceived impact on shipboard leadership arrangement and STCW leadership requirements. The first section included five core open-ended questions, e.g., "as the automation technologies advance, the range of automatable tasks onboard ships are also increasing. On a highly automated ship, systems will perform most of the functions with few crews needed onboard to monitor the system's functioning and intervene if considered necessary. What are the essential leadership competencies you think the remaining onboard crews should have in order to ensure safety and efficiency?"; "If the ship is remotely controlled with no

Table 2 Key statistics regarding the panellists participated in Delphi and AHP

\begin{tabular}{llll}
\hline Criteria of classification & Statistics & Frequency & Percentage (\%) \\
\hline Area of expertise & Ship owning/operating company & 2 & 5.6 \\
& Maritime training institute/provider & 5 & 13.9 \\
& Maritime research & 6 & 16.7 \\
& Professional seafarer (e.g., master, & 22 & 61.1 \\
& $\quad$ chief mate, chief engineer) & & \\
& Other area (e.g., port operator) & 1 & 2.8 \\
Years of experience in shipping & $>15$ & 13 & 36.1 \\
& $11-15$ & 1 & 2.8 \\
& $6-10$ & 8 & 22.2 \\
& $\leq 5$ & 14 & 38.9 \\
\hline
\end{tabular}


seafarer presence onboard, what leadership competencies do you think the people involved (e.g., remote control operators) should have?"

The second part of the questionnaire asked the panellists to evaluate the relevance and importance of 6 STCW KUPs and 3 leadership behavioural categories under both manned and unmanned MASS scenarios, on a 5-point Likert scale from totally disagree (1) to totally agree (5). The consensus in favour of a topic in this study was set to reach above $80 \%$ amongst panellists, as a rigorous standard, for it to be considered as an important leadership competence. To calculate the overall percentage of agreement, the number of times the expert agreed in a particular leadership competence was divided by the total number of ratings performed (Miles et al. 1994). The questionnaire was distributed to the panellists, and the results were then analysed through an abductive coding process in light of STCW leadership requirements (as shown in Table 1), as well as prior research to identify commonalities that represent future leadership competence. In the second round, respondents were required to confirm the results derived from the previous questionnaire. An AHP questionnaire was designed for prioritizing and ranking the leadership competence, identifying the leadership competence that, according to the informants, play principal and decisive roles in future autonomous shipping.

In order to calculate the relative importance of each leadership competence category, a matrix of pairwise comparisons were established for AHP: i.e., Criterion A versus Criterion B. For example, when considering a question such as: "If the ship is remotely controlled with no seafarer presence onboard, which competence do you think is more important than the other for the remote control operators? how much more important?" The judgement/evaluation will then be given on a scale with the values 1, 3, 5, 7 and 9 (Saaty 1980; Podvezko 2009). The higher the value, the more important the corresponding criterion. Experts' judgement will result a set of $n$ objects/criteria with their weights $\left(\mathrm{w}_{1}, \mathrm{w}_{2}, \ldots, \mathrm{w}_{\mathrm{n}}\right)$, which formulate a matrix of comparison:

$$
A=\left[\begin{array}{cccc}
w_{1} / w_{1} & w_{1} / w_{2} & \ldots & w_{1} / w_{n} \\
w_{2} / w_{1} & w_{2} / w_{2} & \ldots & w_{2} / w_{n} \\
\vdots & \vdots & \ddots & \vdots \\
w_{n} / w_{1} & w_{n} / w_{2} & \ldots & w_{n} / w_{n}
\end{array}\right]
$$

The normalized eigenvector of the matrix can be obtained:

$$
\left[\begin{array}{cccc}
w_{1} / w_{1} & w_{1} / w_{2} & \ldots & w_{1} / w_{n} \\
w_{2} / w_{1} & w_{2} / w_{2} & \ldots & w_{2} / w_{n} \\
\vdots & \vdots & \ddots & \vdots \\
w_{n} / w_{1} & w_{n} / w_{2} & \ldots & w_{n} / w_{n}
\end{array}\right]\left[\begin{array}{c}
w_{1} \\
w_{2} \\
\vdots \\
w_{n}
\end{array}\right]=\left[\begin{array}{c}
n w_{1} \\
n w_{2} \\
\vdots \\
n w_{n}
\end{array}\right]=n\left[\begin{array}{c}
w_{1} \\
w_{2} \\
\vdots \\
w_{n}
\end{array}\right]
$$

The corresponding normalized eigenvector of the comparison matrix gives the relative importance of each criteria (i.e., leadership KUP) being compared. The above equation can be represented as:

$$
A v=\lambda v
$$

Accordingly, the AHP pairwise comparison algorithm can be seen as the standard eigenvalue problem. Satty (1979) proposed to utilize Consistency Index (CI) and 
Consistency Ratio (CR) to check the consistency of the comparison matrix. CI is defined as follows:

$$
\mathrm{CI}=(\lambda-n) /(n-1)
$$

This value can be compared with Random Matrix (RI) (Saaty 1979), which is represented as:

$$
\mathrm{CR}=\mathrm{CI} / \mathrm{RI}
$$

The inconsistency, the value of CR, should be less than $10 \%$ in order to be considered as acceptable judgement (Saaty 1979).

\section{Results}

\subsection{Results from round 1: Delphi consensus survey}

The adoption of higher automation in ships does not imply that there is no longer a need for what leaders provide. On the contrary, the consensus from the panellists has shown that leadership remains an essential ingredient for future ship operations under both unmanned and manned MASS. The result generated through Delphi consensus survey, as shown in Table 3, indicates that automation technology for autonomous and unmanned operations will have significant impact on many of the required leadership competences for both management and operational level as set out in STCW 1978 as amended. The 6 leadership KUPs and behavioural categories (B1, B2, B3) will remain as basic leadership shipboard requirements for future shipboard leaders on manned MASS. However, in the remote-controlled and unmanned MASS scenario, 2 out of 6 leadership KUPs, i.e., knowledge of shipboard personnel management and training and knowledge and ability to apply effective resource management (except a subpoint under this KUP: Ability to obtain and maintain situation awareness), were deem no longer relevant and important for remote control operators.

However, the results indicate that there is a need to shift the expectations and change the competency framework for leadership. As mentioned by the panellists in the openended question section, increased automation implies that fewer operators are needed to be present onboard and also implies more dependencies on the expertise, mental resources and collaborations amongst the crews onboard for dealing with all normal and abnormal situations. Crews onboard MASS need to seek for a way to work effectively within the new partnerships between human teams and machines, while being externally connected and agile. As explained by a panellist:

"Since there will be only few crew members onboard, the ability to facilitate effective horizontal collaborations to acquire contributions from each (human) member is perhaps more important compare to top down leadership."

The words commonly associated with future leadership for both shipboard leaders and remote control operators include "remote collaboration," "horizontal management," "delegation skills," "emergency leadership," "technological understanding," "information processing" etc. Inductive analysis of all qualitative responses have 
Table 3 Degree of agreement regarding the relevance of each leadership KUP for MASS

\begin{tabular}{|c|c|c|c|c|}
\hline Notation & $\begin{array}{l}\text { Common knowledge, understanding and } \\
\text { proficiency (KUP) of leadership for both } \\
\text { management and operational level } \\
\text { onboard merchant ships }\end{array}$ & $\begin{array}{l}\text { Relevant under } \\
\text { manned MASS } \\
(\text { degree } 1) ?\end{array}$ & $\begin{array}{l}\text { Relevant under } \\
\text { remotely controlled } \\
\text { MASS (degree } 3) ?\end{array}$ & $\begin{array}{l}\text { Comparison } \\
(\%)\end{array}$ \\
\hline KUP 1 & $\begin{array}{l}\text { Knowledge of shipboard personnel } \\
\text { management and training }\end{array}$ & Yes $(92 \%)$ & No $(63 \%)$ & -29 \\
\hline KUP 2 & $\begin{array}{l}\text { Knowledge of related international } \\
\text { maritime conventions and } \\
\text { recommendations, and national } \\
\text { legislation }\end{array}$ & Yes $(100 \%)$ & Yes $(88 \%)$ & -12 \\
\hline KUP 3 & $\begin{array}{l}\text { Ability to apply task and workload } \\
\text { management including planning and } \\
\text { coordination, personnel assignment, } \\
\text { time and resource constraints, } \\
\text { prioritization }\end{array}$ & Yes $(100 \%)$ & Yes $(100 \%)$ & 0 \\
\hline \multirow[t]{6}{*}{ KUP 4} & $\begin{array}{l}\text { Knowledge and ability to apply effective } \\
\text { resource management }\end{array}$ & Yes $(92 \%)$ & No $(79 \%)$ & 13 \\
\hline & $\begin{array}{l}.1 \text { Ability to allocate, assign, and prioritize } \\
\text { resources }\end{array}$ & Yes $(96 \%)$ & No $(79 \%)$ & 17 \\
\hline & $\begin{array}{l}.2 \text { Ability to initiate and maintain effective } \\
\text { communication on board and ashore }\end{array}$ & Yes $(100 \%)$ & No $(79 \%)$ & 21 \\
\hline & $\begin{array}{l}.3 \text { Ability to make decisions reflect } \\
\text { consideration of team experience }\end{array}$ & Yes $(100 \%)$ & No $(79 \%)$ & 21 \\
\hline & $\begin{array}{l}.4 \text { Assertiveness and leadership, including } \\
\text { motivation }\end{array}$ & Yes $(96 \%)$ & No $(67 \%)$ & 29 \\
\hline & $\begin{array}{l}.5 \text { Ability to obtain and maintain situation } \\
\text { awareness }\end{array}$ & Yes $(100 \%)$ & Yes $(88 \%)$ & 12 \\
\hline \multirow[t]{5}{*}{ KUP 5} & $\begin{array}{l}\text { Knowledge and ability to apply } \\
\text { decision-making techniques }\end{array}$ & Yes $(100 \%)$ & Yes $(92 \%)$ & 8 \\
\hline & $\begin{array}{l}.1 \text { Knowledge and ability to conduct } \\
\text { situation and risk assessment }\end{array}$ & Yes $(100 \%)$ & Yes $(88 \%)$ & 12 \\
\hline & $\begin{array}{l}.2 \text { Knowledge and ability to identify and } \\
\text { generate options }\end{array}$ & Yes $(100 \%)$ & Yes $(83 \%)$ & 17 \\
\hline & $\begin{array}{l}.3 \text { Knowledge and ability to select course } \\
\text { of action }\end{array}$ & Yes $(92 \%)$ & Yes $(92 \%)$ & 0 \\
\hline & $\begin{array}{l}.4 \text { Knowledge and ability to evaluation of } \\
\text { outcome effectiveness }\end{array}$ & Yes $(88 \%)$ & Yes $(88 \%)$ & 0 \\
\hline KUP 6 & $\begin{array}{l}\text { Development, implementation, and } \\
\text { oversight of standard operating } \\
\text { procedures }\end{array}$ & Yes $(92 \%)$ & Yes $(92 \%)$ & 0 \\
\hline B1 & $\begin{array}{l}\text { Caring and supporting (i.e., respect and } \\
\text { trust employees, and care about crew's } \\
\text { needs and empathize with their } \\
\text { problems) }\end{array}$ & Yes $(92 \%)$ & No $(71 \%)$ & 21 \\
\hline B2 & $\begin{array}{l}\text { Controlling and enforcing (i.e., set the } \\
\text { rules by which the teams/organization } \\
\text { runs, use their power to give a reward } \\
\text { or a punishment) }\end{array}$ & Yes $(100 \%)$ & No $(71 \%)$ & 29 \\
\hline B3 & $\begin{array}{l}\text { Participative involvement (i.e., promote } \\
\text { crew's involvement in decision making } \\
\text { and participating in safety activities) }\end{array}$ & Yes $(100 \%)$ & No $(71 \%)$ & 29 \\
\hline
\end{tabular}


highlighted the importance and relevance of an additional leadership competence requirement in relation to the ability to understand and interpret large amounts of information generated through the systems, we coded this as a new competence requirement: "Knowledge and ability to acquire, handle and comprehend large amount of system information." Crews onboard will be required to be systemic thinkers to comprehend the information from various system components and to look for interconnectedness of the issues, address the root cause instead of the obvious symptoms (e.g., alarms, visual signals).

\subsection{Results from round 2: Delphi verification and AHP results}

Based on the results derived from the first round Delphi study, the panellists were invited to confirm the first round results and also to prioritize leadership competences by conducting a set of pairwise comparisons for remote control operators as well as shipboard officers on highly automated ships. The final weighted leadership competence lists and the results of the final ranking are presented in Tables 4 and 5. Data inconsistency was checked (as described in Sect. 3), the resulting ratio is $2.3 \%$ and $2.0 \%$ (less than $10 \%$ ), which indicate that judgements made by the panellists were consistent.

The result indicates, for remote control operators on unmanned ships, the ability to obtain and maintain situation awareness is perceived as the most critical leadership competence requirement, with the highest reported importance weight (30.9\%), for safe and efficient operation. Another competence requirement that has received high level of significance is the knowledge and ability to acquire, handle and comprehend large amount of system information (23.9\%). As the information given by the ship through its various sensor systems will influence and guide the decisions of the remote control operators, the ability to accurately interpret and comprehend the system information is of importance for leaders' decision making. In contrast, knowledge of related international maritime conventions and recommendations and national legislation (KUP 2), as well as the ability to apply task and workload management (KUP 3), were perceived to be less important for remote control operators.

Table 4 Required leadership competence and importance weights for remote control operators of unmanned MASS under degree 3 level of automation

Notation Leadership requirement for remote control operators of unmanned MASS Weight Importance ranking

\begin{tabular}{|c|c|c|}
\hline KUP 4.5 & Ability to obtain and maintain situation awareness & 0.3088 \\
\hline $\begin{array}{l}\text { New } \\
\text { KUP }\end{array}$ & $\begin{array}{l}\text { Knowledge and ability to acquire, handle and comprehend large amount } \\
\text { of system information }\end{array}$ & 2385 \\
\hline KUP 5 & Knowledge and ability to apply decision-making techniques & 0.1904 \\
\hline KUP 6 & $\begin{array}{l}\text { Development, implementation, and oversight of standard operating } \\
\text { procedures }\end{array}$ & 0.1027 \\
\hline KUP 3 & Ability to apply task and workload management & 0.0830 \\
\hline KUP 2 & $\begin{array}{l}\text { Knowledge of international maritime conventions and recommendations, } \\
\text { and related national legislation }\end{array}$ & 0.0766 \\
\hline
\end{tabular}


Table 5 Required leadership competence for shipboard officers on manned MASS under degree 1 automation

\begin{tabular}{|c|c|c|c|}
\hline Notation & Leadership requirement for shipboard leaders on manned MASS & Weight & $\begin{array}{l}\text { Importance } \\
\text { ranking }\end{array}$ \\
\hline KUP 5 & Knowledge and ability to apply decision-making techniques & 0.1554 & 1 \\
\hline $\begin{array}{l}\text { New } \\
\text { KUP }\end{array}$ & $\begin{array}{l}\text { Knowledge and ability to acquire, handle and comprehend large amount of } \\
\text { system information }\end{array}$ & 0.1454 & 2 \\
\hline B3 & $\begin{array}{l}\text { Participative involvement (i.e., promote crew's involvement in decision } \\
\text { making and participating in safety activities) }\end{array}$ & 0.1105 & 3 \\
\hline B1 & $\begin{array}{l}\text { Caring and supporting (i.e., respect and trust employees, and care about } \\
\text { crew's needs and empathize with their problems) }\end{array}$ & 0.1029 & 4 \\
\hline KUP 4 & Knowledge and ability to apply effective resource management & 0.1007 & 5 \\
\hline KUP 6 & $\begin{array}{l}\text { Development, implementation, and oversight of standard operating } \\
\text { procedures }\end{array}$ & 0.0913 & 6 \\
\hline KUP 3 & Ability to apply task and workload management & 0.0912 & 7 \\
\hline B2 & $\begin{array}{l}\text { Controlling and enforcing (i.e., set the rules by which the } \\
\text { teams/organization runs, use their power to give a reward or a punish- } \\
\text { ment) }\end{array}$ & 0.0795 & 8 \\
\hline KUP 2 & $\begin{array}{l}\text { Knowledge of related international maritime conventions and } \\
\text { recommendations, and national legislation }\end{array}$ & 0.0622 & 9 \\
\hline KUP 1 & Knowledge of shipboard personnel management and training & 0.0608 & 10 \\
\hline
\end{tabular}

Under manned MASS scenario, the autonomous operating system takes main role for ship operations, but humans will still play an important role in monitoring, planning and optimizing the logistics, where more leadership roles and tasks be potentially placed on obtaining and maintaining situation awareness through systems thinking and predications. The ability to take a holistic approach to analysis that focuses not only on an individual system (e.g., ECDIS, autopilot) but also on how different systems would influence one another within the whole system would be an important competence to improve situational awareness and enable more effective problem solving and decision making. By looking at the priority weights in Table 5, knowledge and ability to apply decision-making techniques $(15.54 \%)$, knowledge and ability to acquire, handle and comprehend large amount of system information (14.54\%) were reported to have a high level of importance for shipboard leaders on highly automated ships. The reduced crew size onboard implies that the knowledge of shipboard personnel management and training would become the least relevant and important from the shipboard leaders' perspective.

\section{Discussion}

\subsection{Implication of unmanned, remotely controlled MASS scenario on leadership}

As acknowledged in recent research (Samani et al. 2012; Wesche and Sonderegger 2019), humans are not necessarily a mandatory component for leadership to occur. Computer agents could take the lead to "guide, structure and facilitate activities and 
relationship in a group and organization" (Wesche and Sonderegger 2019). In the case of unmanned, remotely controlled MASS scenarios where the ship is autonomous with no human operators to intervene unless the system requests so, the leadership functions onboard would be replaced by automated decision-making, but not necessarily all of the manual functions required to successfully operate the ship autonomously (i.e., system monitoring, route planning etc.). The information given by the ship through its various sensor systems will influence and direct the decisions made by the remote control operators. The remote control operators will need to trust, completely reliant and blindly accept the information sent by the systems. Accordingly, the hierarchical leadership relations in autonomous ship operations under degree 3 level of autonomy would differ in comparison with degree 1 mode of operation, as illustrated in Fig. 2. However, delegating shipboard leadership decisions to the system also has moral ramifications, as human leaders are in no way able to (or allowed to, or have competence to) participate in, or contribute to, the decision-making process onboard of ship.

Several researchers have discussed the opportunities and also challenges of implementing remote and unmanned control solutions for safety and efficiency of ship operations. Man et al. (2016) analysed shore-based unmanned ships and found that by monitoring a ship remotely, the operators may have reduced senses of the ship. It is difficult, or impossible, to develop the same level of "feeling" and bodily understanding regarding the ships' status, including smells, vibrations, variation or movement of the ship and how it is reacting to the external environment (e.g., waves, currents, winds etc.) (Mallam and Lundh 2016; WMU and ITF 2019). This implies that the operators in the control centre will have limited ship senses. The tactic knowledge that is developed by the navigators onboard, which aid in successful ship manoeuvring, is needed to be transferred to shore. Many knowledge and skills are not relevant that once were extremely important, as illustrated in our findings.

A parallel can be drawn between concepts of unmanned ships and military unmanned aerial vehicles (popularly known as "drones"). Upon initial introduction of drones, the US Air Force implemented conventional aircraft pilots in their land-based control centres. However, due to the difference in skills required between conventional flying and land-based drone flying, the competence requirements, operator profiles and training programs were redefined (Hoagland 2013; FAA 2020). The introduction of drone technology and the ability to fly aircraft from land-based locations are changing our traditional concepts of what it is to be an "aircraft pilot," similar to what the maritime domain now faces as new technologies redefine the concept, skills and work profile of what future "seafarers" will be.

Given the impact of automation, the need to retrain or reskill the future operators would represent as a challenge for the industry. Furthermore, due to the large amount of information displayed in the shore-based remote control centre, information overloading could also be a potential problem that influence the accuracy of situation awareness and decision making, especially if the operator is overseeing several ships at one time. The systems will be more complex, which indicates increased ambiguity and uncertainty to comprehend and make sound decisions. These challenges threaten the reliability of remotely controlled MASS and also increase the complexity to operate safely and efficiently from the shore-side. 


\subsection{Implication of manned MASS Scenario on leadership}

In the manned MASS configuration, operational decisions are delegated to the system, and it performs the tasks under direct supervision by the crews onboard. The autonomous operating system serves as substitute for deck officers in handling routine navigational tasks, as routine operational processes are more likely to be automated as they occur repetitive enough to enable strategic preparation and the decision rules and algorithms to be developed. It can be expected that the decision points that will be faced by ship crews are more likely to involve exceptions, unusual problems or emergency situations that could not be sufficiently dealt by an autonomous operating system. These scenarios will challenge the leaders to deal with more complex technical problems that may not have been faced frequently, or at all, in conventional ship operations. This will require the ship crews to be able to demonstrate a higher system understanding so that adequate emergency leadership can be exercised in case of abnormal situations. Further, they should also be able to rapidly bring together the information required for the problems, making instantaneous decisions through interactions with the crew and the technological systems.

Although the crew composition of manned MASS scenarios are currently unknown and unproven, it can be projected that the increased automation implementation implies that fewer operators will be needed to be present onboard. This also implies more dependencies on the expertise, mental resources and collaborations among the few crew onboard to carry out the tasks and deal with all possible situations. Fewer crew onboard will also imply that the system will take over more parts of the human leaders' interaction with their subordinates, more functions and power will be given to the autonomous operating system. The crew onboard and the ships' automation systems will be no longer in a master/slave relationship but gradually on a more equal level of hierarchy. The shipboard officers will need to consider not only how to interact and collaborate with other human teammates but also how to work with the machines that have non-negligible cognitive capacity and high intelligence. This situation implies that leadership competence should be developed beyond the classical leadership knowledge recognized in human-human interaction scenarios, but to consider and construct leadership skills that can help leaders to build good partnership with autonomous systems for operational efficiency in human-robot navigation scenarios (Samani et al. 2012; Wesche and Sonderegger 2019). A new host of leadership and teamwork questions is likely to be emerged in the future, which need to be further explored and addressed to ensure human-robot teams to be effective (Gombolay et al. 2015a; Gombolay et al. 2015b).

\subsection{Limitations}

Several limitations of this study deserve to be mentioned. The area of autonomous and remote operation of vessels is still an immature field. The result presented here can form an impartial basis for further discussion regarding MASS and its policy consideration. The present study employed AHP to obtain the importance ranking of leadership competence, as it is one of the most frequently used multi-criteria decision making methods (Velasquez and Hester 2013). A limitation is that AHP model assumes independences among all alternatives. To validate the results presented in this paper, 
future research should be conducted to verify the independencies through statistical analysis using larger sample sizes. Further, future studies could also use other approaches, e.g., Technique for Order of Preference by Similarity to Ideal Solution (TOPSIS), to estimate the relative weights of each leadership competence under different autonomous operation situations. The results of such future studies can then be compared with those presented in this study. In addition, nationality, cultural background could have an influence on the selection and utilization of different leadership strategies. Future research may also consider the cultural background of the experts; the difference in the ranking could also provide interesting information for future seafarers.

\subsection{Future research directions}

Future research on leadership for safety-critical systems must address the role of humans and effective human leadership within fast-changing and increasingly automated organizations. The present study generates several directions for future research exploration:

First, as O'Heigeartaigh (2013) remarked that "When a machine is 'wrong', it can be wrong in a far more dramatic way, with more unpredictable outcomes, than a human could" (para. 12). The ethical, legal and other threshold issues have continued relevancy within the discussion of autonomous operating systems. How should the accountability of systems for Degree 3 and 4 level of autonomy be established, and should the machine always take the lead? How will humans come to accept and follow a computer leader is an area which needs to be further evaluated. Future research should also look into the accountability and ethical issues in the development of autonomous operating systems to suggest legal and ethical standards and laws in parallel of technological development.

Second, the significantly enhanced level of digital dependence and automation in the maritime industry has already, and will further reduce onboard manning levels. This has also shifted the role from direct interaction and control to more supervisory activities. This will continue to pose new attentional and cognitive demands for seafarers (Lützhöft and Dekker 2002). Reskilling and retraining are of importance for seafarers to keep updated with the new risk portfolio related to the new technologies and to create needed skills and awareness for ensuring safety and reliability in ship operations. This also has implication on the infrastructure and Maritime Education and Training (MET) industry.

Third, as autonomous and unmanned ships will further alter the nature of ship operations and team composition, it cannot be assumed that such vessels will still be safe based exclusively on the knowledge that we developed through learning from earlier systems (Komianos 2018). Future research can delve deeper into the leadership and management issues for all organizational levels and explore the applicable leadership models for effective management of autonomous ship operations.

Furthermore, reducing or eliminating the onboard crews should be based on the provision of technical solutions that could perform equally good or even better performance in comparison with crew in attendance with regards to safety, reliability and efficiency. Future research should be conducted to compare and further explore the competitive advantage among different operational scenarios and also to identify the 
most optimal alternative for all stakeholders in the maritime domain and within specific industrial sectors.

\section{Conclusion}

Technology exists inside the context of human society. To understand and advance a technology requires adequate and sufficient understanding not only of its mechanisms but also the cultural, social and environmental milieu in which it operates. The move to autonomous shipping is a natural progression in the evolution of maritime operations and the direction of societal functioning in general. However, utilizing intelligent algorithms and their burgeoning decision-making potential indicates the need for changes and reorganization of people/levels in the system. Automation technology is gradually taking centre stage and changing the principles and practice of leadership onboard ships. It is important to consider how to better prepare the current and future leaders to meet the challenges presented by technological disruption.

In this paper, we have explored if the disruptive changes with regards to the implementation of autonomous technologies will have an influence on leadership practices and STCW competence requirements. We have also discussed the new leadership competences that should be accrued by the personnel involved in the future configurations of ship operations. The results revealed that the (i) knowledge and ability to apply decisionmaking techniques, (ii) knowledge and ability to acquire, handle and comprehend large amount of system information, and (iii) the ability to obtain and maintain situation awareness could be the main determinants for safe and efficient operation of MASS. These research findings could add value to the ongoing policy discussion regarding the impact of MASS on IMO instruments and, in particular, the STCW 1978 as amended. The leadership competence requirement derived in this study could contribute to the revision of STCW Table A-II/1, Table A-III/1, Table A-II/2 and Table A-III/2. This research can also be used as an input for Maritime Education and Training (MET) institutes in order to adapt their MET programs and maintain relevancy of their training practices to effectively prepare current and future leaders for successful ship operations of the future.

\section{Acknowledgements Open Access funding provided by University Of South-Eastern Norway.}

Open Access This article is licensed under a Creative Commons Attribution 4.0 International License, which permits use, sharing, adaptation, distribution and reproduction in any medium or format, as long as you give appropriate credit to the original author(s) and the source, provide a link to the Creative Commons licence, and indicate if changes were made. The images or other third party material in this article are included in the article's Creative Commons licence, unless indicated otherwise in a credit line to the material. If material is not included in the article's Creative Commons licence and your intended use is not permitted by statutory regulation or exceeds the permitted use, you will need to obtain permission directly from the copyright holder. To view a copy of this licence, visit http://creativecommons.org/licenses/by/4.0/.

\section{References}

Bertram V (2016). Autonomous ship technology - smart for sure, unmanned maybe. RINA, Royal Institution of Naval Architects - Smart Ship Technology 2016, Papers 
Biernacki P, Waldorf D (1981) Snowball sampling: problems and techniques of chain referral sampling. Sociological Methods \& Research 10(2):141-163

Bolden R, O'Regan N (2016) Digital disruption and the future of leadership: an interview with Rick Haythornthwaite, Chairman of Centrica and MasterCard. Journal of Management Inquiry 25(4):438-446

Cambanis DG (2011). Challenge to the industry securing skilled crews in today's market place. The Global Survey.[Online] Available: http://www2. deloitte.com/con-tent/dam Deloitte/global/08072013. pdf.(October 21st, 2014)

Cartner JAC, Fiske RP, Leiter TL (2009) The international law of the shipmaster. Informa, London

Chelst K and Canbolat YB (2011). Value-added decision making for managers, CRC Press.

Danish Maritime Authority, D. M (2017). Analysis of regulatory barriers to the use of autonomous ships final report. https://www.dma.dk/Documents/Publikationer/Analysis\%20of\%20Regulatory\%20Barriers $\% 20$ to $\% 20$ the $\% 20$ Use $\% 20$ of\%20Autonomous\%20Ships.pdf, tech. rep

Eid J, Mearns K, Larsson G, Laberg JC, Johnsen BH (2012) Leadership, psychological capital and safety research: Conceptual issues and future research questions. Safety Science 50(1):55-61

FAA (2020). Become a Drone Pilot. F. A. A. U. S. D. o. Transportation. Washington, https://www.faa. gov/uas/commercial_operators/become_a_drone_pilot/.

Gombolay MC, Gutierrez RA, Clarke SG, Sturla GF, Shah JA (2015a) Decision-making authority, team efficiency and human worker satisfaction in mixed human-robot teams. Autonomous Robots 39(3):293312

Gombolay MC, Huang C, Shah J (2015b). Coordination of human-robot teaming with human task preferences.

Griffin MA, Neal A (2000) Perceptions of safety at work: a framework for linking safety climate to safety performance, knowledge, and motivation. Journal of Occupational Health Psychology 5(3):347

Hoagland BT (2013). Manning the next unmanned air force: developing RPA pilots of the future, Brookings Institution Washington DC.

Hsu C-C, Sandford BA (2007) The Delphi technique: making sense of consensus. Practical Assessment, Research \& Evaluation 12(10):1-8

IMO (2017). International Convention on Standards of Training, Certification and Watchkeeping for Seafarers (STCW) 1978, as amended in 1995/2010. International Maritime Organisation, London, UK.

IMO (2018). Working group report in 100th session of IMO Maritime Safety Committee for the regulatory scoping exercise for the use of maritime autonomous surface ships (MASS). MARITIME SAFETY COMMITTEE 100th session MSC 100/ WP.8.

Kavallieratos G, Katsikas S, Gkioulos V (2019). Cyber-attacks against the autonomous ship. Lecture Notes in Computer Science (including subseries Lecture Notes in Artificial Intelligence and Lecture Notes in Bioinformatics). 11387 LNCS: 20-36.

Kim T-E, Gausdal AH (2017) Leading for safety: a weighted safety leadership model in shipping. Reliability Engineering \& System Safety 165:458-466

Kim T-E, Gausdal AH (2020) Leaders' influence tactics for safety: an exploratory study in the maritime context. Safety 6(1):8

Kim T-E, Nazir S, Øvergård KI (2016) A STAMP-based causal analysis of the Korean Sewol ferry accident. Safety science 83:93-101

Kim T-E, Sharma A, Gausdal AH, Chae CJ (2019) Impact of automation technology on gender parity in maritime industry. WMU Journal of Maritime Affairs 18(4):579-593. https://doi.org/10.1007/s13437019-00176-w

Kitada M, Baldauf M, Mannov A, Svendsen PA, Baumler R, Schröder-Hinrichs J-U, Dalaklis D, Fonseca T, Shi X and Lagdami K (2018). Command of vessels in the era of digitalization, Springer

Komianos A (2018). The autonomous shipping era. Operational, regulatory, and quality challenges. TransNav: International Journal on Marine Navigation and Safety of Sea Transportation 12

Kooij C, Loonstijn M, Hekkenberg RG and Visser K (2018). Towards autonomous shipping: operational challenges of unmanned short sea cargo vessels. Marine Design XIII

Lützhöft MH, Dekker SWA (2002) On your watch: automation on the bridge. Journal of Navigation 55(1):8396

Mallam SC, Lundh M (2016) The physical work environment and end-user requirements: investigating marine engineering officers' operational demands and ship design. Work 54(4):989-1000

Mallam SC, Ernstsen J, Nazir S (2019a) Safety in shipping: investigating safety climate in Norwegian maritime workers. SAGE Publications Sage CA, Los Angeles

Mallam SC, Nazir S and Sharma A (2019b). The human element in future Maritime Operations-perceived impact of autonomous shipping. Ergonomics 
Man Y, Lundh M and Porathe T (2016). Seeking harmony in shore-based unmanned ship handling: from the perspective of human factors, what is the difference we need to focus on from being onboard to onshore? Human Factors in Transportation, CRC Press: 81-90

Miles MB, Huberman AM, Huberman MA and Huberman M (1994). Qualitative data analysis: an expanded sourcebook, sage

Montewka J, Wróbel K, Heikkila E, Valdez-Banda O, Goerlandt F and Haugen S (2018). Challenges, solution proposals and research directions in safety and risk assessment of autonomous shipping. PSAM 2018 Probabilistic Safety Assessment and Management

Murry JW Jr, Hammons JO (1995) Delphi: a versatile methodology for conducting qualitative research. The Review of Higher Education 18(4):423-436

Podvezko V (2009). Application of AHP technique. Journal of Business Economics and Management(2): 181189

Porathe T, Hoem ÅS, Rødseth ØJ, Fjørtoft KE and Johnsen SO (2018). At least as safe as manned shipping? Autonomous shipping, safety and "human error". Safety and Reliability-Safe Societies in a Changing World. Proceedings of ESREL 2018, June 17-21, 2018, Trondheim, Norway

Pribyl ST, Vessels AMWA (2018) How an emerging disruptive technology is poised to impact the maritime industry much sooner than anticipated. RAIL Robotics. Artificial Intelligence \& Law/January 1(1):17-25

Pribyl ST, Weigel AM (2018) Autonomous vessels: how an emerging disruptive technology is poised to impact the maritime industry much sooner than anticipated. The Journal of Robotics, Artificial Intelligence \& Law 1:17-25

Ringbom H (2019) Regulating autonomous ships — concepts, challenges and precedents. Ocean Development \& International Law 50(2-3):141-169

Saaty TL (1979) Applications of analytical hierarchies. Mathematics and Computers in Simulation 21(1):1-20

Saaty TL (1980). The analytic hierarchy process: planning, priority setting, resource allocation. New York ; London, McGraw-Hill International Book Co.

Saaty TL (2002) Decision making with the analytic hierarchy process. Scientia Iranica 9(3):215-229

Saaty (2003) Decision-making with the AHP: why is the principal eigenvector necessary. European Journal of Operational Research 145(1):85-91

Samani HA, Koh JTKV, Saadatian E, Polydorou D (2012). Towards robotics leadership: an analysis of leadership characteristics and the roles robots will inherit in future human society, Springer

Santos TA and Guedes Soares C (2018). Economic feasibility of an autonomous container ship. Maritime Transportation and Harvesting of Sea Resources

Sharma A, Kim T, Nazir S, Chae C (2019). Catching up with time? Examining the STCW competence framework for autonomous shipping, Ergoship conference: 87-93

STCW (1978). International Convention on Standards of Training, Certification and Watchkeeping 1978, as amended IMO

Titanicfacts (2020). Titanic Engineering Crew: https://titanicfacts.net/titanic-crew/. Retrieved 13th January, 2020

Vaidya OS, Kumar S (2006) Analytic hierarchy process: an overview of applications. European Journal of operational research 169(1):1-29

Velasquez M, Hester PT (2013) An analysis of multi-criteria decision making methods. International journal of operations research 10(2):56-66

Wesche JS, Sonderegger A (2019) When computers take the lead: the automation of leadership. Computers in Human Behavior 101:197-209

WMU and ITF (2019). Transport 2040: automation, technology, employment - the future of work. World Maritime University.

Publisher's note Springer Nature remains neutral with regard to jurisdictional claims in published maps and institutional affiliations. 